Original Article

\title{
Effects of endurance exercise and half-bath on body composition, cardiorespiratory system, and arterial pulse wave velocity in men with intellectual disabilities
}

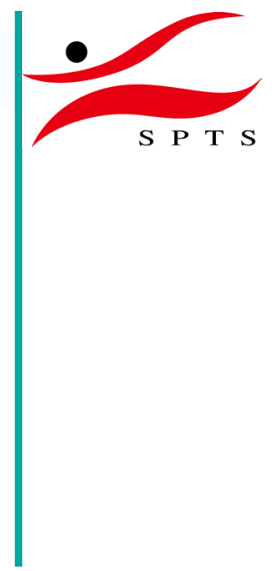

\author{
SEung-Suk Kim, $\mathrm{PhD}^{1)}$ \\ 1) Department of Sports and Health Management, Mokwon University: Daejeon 302-729, \\ Republic of Korea
}

\begin{abstract}
Purpose] The purpose of this study was to investigate the effects of endurance exercise and half-bath on body composition, cardiorespiratory system, and arterial pulse wave velocity of men with intellectual disabilities. [Subjects and Methods] Twenty-four men with intellectual disabilities, but capable of learning, were randomly assigned to aerobic exercise $(\mathrm{N}=8)$, half-bath $(\mathrm{N}=8)$, or control $(\mathrm{N}=8)$ treatment groups. Over the 12-week treatment period, the aerobic exercise group did treadmill and stationary bicycle. The half-bath treatment group was placed in a sitting position in a $39-40^{\circ} \mathrm{C}$ bath for 10 minutes. [Results] The aerobic exercise group showed a significant decrease in body fat than those in the half-bath and control groups. In addition, there was an increase in the respiratory system of the aerobic exercise group but no increase in the half-bath and control groups. The arterial pulse wave velocity change was greatest in the aerobic exercise group, but the half-bath group also showed a velocity change from that in the control group. [Conclusion] Aerobic exercise and a half-bath can have positive effects on improving body composition, respiratory system, and vascular function of people with intellectual disabilities.

Key words: Half-bath, Cardiorespiratory system, Intellectual disabilities
\end{abstract}

(This article was submitted Mar. 7, 2017, and was accepted Apr. 25, 2017)

\section{INTRODUCTION}

Korean government operates special schools and vocational training centers for the disabled in Korean cities and provinces. Such programs are designed to support the attainment of a healthy life through participation in regular physical activities. However, due to insufficient budget and manpower, the government program cannot reach its full potential, thus there is room for improvement. Especially, the cognitive ability of men with intellectual disabilities is significantly lower than that of the general population, and many disabled find it difficult to perform voluntary and/or regular physical activities ${ }^{1)}$. Draheim ${ }^{2)}$ emphasized the need for dietary control and physical activity in adults with intellectual disabilities as most of whom are at risk for cardiovascular disease. As such, many people with intellectual disabilities are weak or obese due to their physical disabilities $^{3)}$. This increases their potential for developing various geriatric diseases ${ }^{3)}$. Therefore, there is a need to emphasize the necessity of regular physical activity among the disabled. In order to develop a basic exercise program that can lead to a healthy life for the intellectually disabled, this study investigated the effects of endurance exercise and half-bath treatments on body composition, the cardiorespiratory system, and arterial pulse wave velocity in men with intellectual disabilities. 


\section{SUBJECTS AND METHODS}

Subjects included 12 men from the Korea Employment Promotion Agency and 12 from the H Welfare Foundation. Other than intellectual disability, the 24 subjects had no medically overlapping disabilities and had no experience in performing regular exercise. The subjects were randomly assigned to one of three groups: aerobic exercise group ( $\mathrm{N}=8 ;$ age $=19.3 \pm 1.2$ yrs; height $=163.2 \pm 2.6 \mathrm{~cm}$; weight $=65.6 \pm 1.5 \mathrm{~kg}$; body fat=32.3 $\pm 1.6 \%)$, the half-bath group $(\mathrm{N}=8$; age $=18.9 \pm 2.5 \mathrm{yrs}$; height $=165.8 \pm 1.9 \mathrm{~cm}$; weight $=66.8 \pm 1.9 \mathrm{~kg}$; body fat=33.0 $\pm 1.5 \%)$, and the control group $(\mathrm{N}=8$; age $=20.2 \pm 1.1 \mathrm{yrs}$; height $=162.8 \pm 2.1 \mathrm{~cm}$; weight=65.5 $\pm 1.4 \mathrm{~kg}$; body fat=32.4 $\pm 1.1 \%$ ). Subjects were not allowed to eat for 4 hours before treatment and exercise for 12 hours before treatment ${ }^{4}$.

Bioelectrical impedance instrument (InBodyJ20, Bio-Space, Seoul, Korea) was used for measuring the body composition. Before the exercise tolerance was estimated by using the Balke-Ware protocol. The speed of the treadmill was fixed at 3.3 miles per hour (mph) with an initial slope of $2 \%$, which was increased by $1 \%$ every minute. Heart rate, respiratory, and circulatory variables were recorded by using an electrocardiograph instrument (ECG; CH-2000, Cambridge, Switzerland) and a gas analyzer (quark b2, Italy). In addition, the vessel compliance was measured in a lying state by using a vessel compliance equipment (PWV 3.0-K_M TEC, Korea).

The aerobic exercise program was performed between 50-70\% HRmax. During the study treatment period, two 15-minute exercise periods were performed within a 50-minute period 5 times a week for 12 weeks. To ensure accurate exercise intensity during exercise, a Polar heart rate monitor (Polxar Electro, Technogym, Finland) and the receiver (S710i, Polar, Finland) was used.

Participants in the half-bath group were bathed five times a week for twelve weeks in the H sauna located in D city, district Y. Half-bath group participants were placed in a sitting position in a $39-40^{\circ} \mathrm{C}$ bath for 10 minutes. Bath water level was kept below the navel and during the post-bath 5-minute rest period, the subject's body temperature was reduced for 1 minute in tepid and cold water by using a shower. Drinks were provided to prevent dehydration. This process was repeated 3 times per day for a total bathing time of 30 minutes per day. Meanwhile, the control subjects did not participate in any exercise program or half-bath treatment.

All data obtained in this study were analyzed by using SPSS 20.0 version (IBM, Armonk, NY, USA). Descriptive statistics were used to assess means and standard deviations of subjects' physical characteristics. To assess differences in the measured variables among the groups, and by measurement period, results were analyzed by performing repeated two-way ANOVA. The significance level was set at $\mathrm{p}<0.05$. All subjects' parents were informed of the content and purpose of the experiment and all provided written informed consent before beginning the study. The experiment was approved by the Institutional Review Board of Mokwon University.

\section{RESULTS}

The results of this study are summarized in (Table 1). According to those results, body composition, maximal oxygen uptake, heart rate, and arterial pulse wave velocity were significantly different among the groups. There were also differences related to time of measurement and interaction.

Table 1. Blood composition, cardiorespiratory function, pulse wave velocity change

\begin{tabular}{llcccc}
\hline & \multicolumn{1}{c}{ Group } & Pre-test & Post-test & Source & $\mathrm{F}$ \\
\hline \multirow{3}{*}{ Items } & Aerobic exercise & $65.6 \pm 1.5$ & $61.3 \pm 1.6$ & group & $11.475^{* *}$ \\
& Half bath & $66.8 \pm 19$ & $63.1 \pm 1.1$ & time & $13.310^{* *}$ \\
& Control & $65.5 \pm 1.4$ & $66.1 \pm 0.5$ & group*time & $16.759^{* * *}$ \\
\hline \multirow{3}{*}{ Body fat (\%) } & Aerobic exercise & $32.3 \pm 1.6$ & $27.5 \pm 1.1$ & group & $5.116^{* *}$ \\
& Half bath & $33.0 \pm 1.5$ & $29.7 \pm 1.6$ & time & $7.106^{* *}$ \\
& Control & $32.4 \pm 1.1$ & $33.1 \pm 1.0$ & group*time & $9.096^{* * *}$ \\
\hline \multirow{3}{*}{ VO2max (m1/kg/min) } & Aerobic exercise & $25.12 \pm 1.21$ & $33.07 \pm 2.37$ & group & $7.680^{*}$ \\
& Half bath & $26.18 \pm 1.20$ & $27.07 \pm 1.10$ & time & $8.223^{*}$ \\
& Control & $27.13 \pm 1.01$ & $27.05 \pm 1.00$ & group*time & $9.618^{* *}$ \\
\hline \multirow{3}{*}{ HRmax (beat/min) } & Aerobic exercise & $164.51 \pm 1.88$ & $171.22 \pm 2.77$ & group & $38.536^{*}$ \\
& Half bath & $165.87 \pm 1.05$ & $167.55 \pm 1.40$ & time & $43.831^{*}$ \\
& Control & $166.77 \pm 1.20$ & $166.81 \pm 1.04$ & group*time & $39.273^{* *}$ \\
\hline \multirow{2}{*}{ Pulse wave velocity (m/sec/height) } & Aerobic exercise & $1.63 \pm 0.03$ & $1.53 \pm 0.06$ & group & $21.181^{*}$ \\
& Half bath & $1.62 \pm 0.05$ & $1.57 \pm 0.03$ & time & $37.1933^{* *}$ \\
& Control & $1.64 \pm 0.04$ & $1.64 \pm 0.03$ & group*time & $39.760^{* * *}$ \\
\hline \multirow{2}{*}{ p } & & & & &
\end{tabular}

${ }^{*} \mathrm{p}<0.05, * * \mathrm{p}<0.01, * * * \mathrm{p}<0.001$ 


\section{DISCUSSION}

The results of this study showed a significant improvement of body composition in the exercise and half-bath treatment groups. These results are consistent with those in previous studies. Lee ${ }^{5)}$ reported that when students with learning disability engage in extracurricular physical activities, their abdominal fat decreased markedly. Shin ${ }^{6)}$ reported that students with learning disorders who participated in basketball programs showed positive changes in their physical health and fitness. Interestingly, the change in body composition in this study's half-bath group would be the result of increasing the body temperature rather than from exercise ${ }^{7,8)}$. It is assumed that the half-bath facilitated increased blood supply to peripheral blood vessels and promoted metabolism, thereby reducing body weight and body fat ${ }^{7,8)}$. This present study was conducted with the intellectual disability without any disorders. However, the disabled usually have a lower flexibility and strength. The half-bath may cause the lymphatic fluid and venous blood to shrink in the hands and feet. It is necessary to monitor the subject's face color, eyes, and conversation at the time of exercise program and half-bath treatment.

In this study, the maximum oxygen uptake, HRmax, and maximum ventilation were also significantly increased after 12 weeks of treatment only in exercise group. Park ${ }^{1)}$ reported that participation in aerobic exercise programs resulted in statistically significant increases in oxygen uptake, ventilation, and heart rate maxima among the blind and visually impaired patients. Evans and Rosenberg ${ }^{9}$ reported that maximum oxygen uptake increased by $15 \%$ after 16 weeks of physical training of intellectually disabled subjects.

This study also found that the arterial wave velocity and the arterial pulse wave velocity were significantly reduced in both the exercise and half-bath groups from that in the control group, indicating that the blood vessel compliance was improved in the exercise and half-bath treatment groups. The results of previous studies ${ }^{10,11)}$ are consistent with this study. Klemsdal et al. ${ }^{10)}$ reported an increase in blood vessel compliance after exercise in subjects with atherosclerosis. Koichiro et al. ${ }^{11)}$ reported on the results of a 16-week aerobic exercise program for middle-aged men. After the end of the program, there was a significant increase in the vascular elasticity of the carotid artery and a significant decrease in systolic blood pressure.

In summary, this study and previous studies indicate that regular physical activity improves vascular function, which can prevent cardiovascular disease and increase cardiovascular health. However, it is difficult for people with intellectual disabilities to participate in exercise programs as they often need assistance due to their associated physical disabilities. Therefore, more support is needed to improve the well-being of the disabled.

\section{REFERENCES}

1) Park JJ: The effect of aquatic exercise on body composition and blood lipids in obese mentally retarded children. J Sport Leis Stud, 1999, 12: 397-410.

2) Draheim CC: Cardiovascular disease prevalence and risk factors of persons with mental retardation. Ment Retard Dev Disabil Res Rev, 2006, 12: 3-12. [Medline] [CrossRef]

3) McArdle WD, Magel JR: Physical work capacity and maximum oxygen uptake in treadmill and bicycle exercise. Med Sci Sports, 1970, 2: 118-123. [Medline]

4) Heyward VH: Advanced Fitness Assessment Exercise prescription. IL: Human Kinetics, 2000.

5) Lee BJ: Effects of participation in an after-school physical activity program on the body composition of students with intellectual disability. J Adapt Phys Activ, 2007, 15: 167-181.

6) Shin YA, Kim JT, Suk MH, et al.: Effect of basketball program on body composition, metabolic risk factors and physical fitness in overweighted students with intellectual disability. J Adapt Phys Activ, 2010, 18: 111-126.

7) Kim SS, Shin MS, Bae JJ, et al.: The study of low frequency current and thermic therapy and exercise on body composition and circumference of obese women. J Sport Leis Stud, 2003, 19: 1071-1082.

8) Kim IK: The effect of sauna and half bath on systolic blood pressure, heart rate and vascular compliance among middle-aged men. Kor Sport Res, 2006, 17: 319-328.

9) Evans W, Rosenberg IH, Thompson J: Biomarkers: the 10 determinants of aging you can control. New York: Simon \& Schuster, 1991.

10) Klemsdal TO, Moan A, Kjeldsen SE: Effects of selective angiotensin II type 1 receptor blockade with losartan on arterial compliance in patients with mild essential hypertension. Blood Press, 1999, 8: 214-219. [Medline] [CrossRef]

11) Hayashi K, Sugawara J, Komine H, et al.: Effects of aerobic exercise training on the stiffness of central and peripheral arteries in middle-aged sedentary men. Jpn J Physiol, 2005, 55: 235-239. [Medline] [CrossRef] 